Nordisk Tidsskrift for Kriminalvidenskab 2010

\title{
VÅLD SOM ETT (BRA) SAMHÄLLSPROBLEM
}

\section{Av PROFEsSOR Felipe EstradA}

In Scandinavia, as in many other European countries, violence constitutes an important focus for the public and political debate on crime. Much of what is said in the public debate, and done in the field of criminal policy, stems from a perception that violence is on the increase. This paper challenges the view that violence is rapidly increasing. Instead it is argued that the way violence is viewed in society and the subsequent response to violent offending have changed, leading to a deviancy amplification spiral. The discussion highlights the role of neo-liberal policies and the media as actors and arena, respectively, in the creation of this altered reaction. *

Debatten kring våldsutvecklingen kännetecknas i alla nordiska länder av beskrivningar om en ständigt ökande och grövre våldsbrottslighet. Forskarvärldens analyser av våldsutvecklingen ger dock en annan bild. En uppenbar fråga är vad detta beror på. Är det vi forskare som misslyckats med att nå ut med hur kunskapsläget ser ut, eller är vi helt enkelt inte trovärdiga i en tid när "alla vet" att våldet ökar? Frågar man skribenter på nyliberala eller konservativa ledarsidor verkar det senare mest troligt.

"Väck en kriminolog mitt $i$ natten och han kommer att utbrista - brottsligheten har inte ökat!" (Problemet med kriminologerna, Expressen 2008-04-13)

Omfattningen av våldsbrott är självfallet inte helt lätt att avgöra. Om en händelse i ett visst läge ska uppfattas som våld eller hot om våld är något som skiljer sig mellan olika situationer och grupper. Vad som uppfattas som våld förändras också över tid. Det finns under de senaste decennierna en tydlig förändring i vårt samhälle mot en större känslighet för vad som ska uppfattas som våld och hur det skall kontrolleras. Jag skall här kortfattat presentera några undersökningar som visar på utvecklingen av uppmärksamheten av våldsbrott och samhällets reaktion på våld (utförligare i Estrada 1997, 1999, 2004 och 2006). Studierna fungerar som underlag för en vidare diskussion kring samhällets förändrade reaktion kring brottslighet.

\footnotetext{
* Title in English: Violence as a (Suitable) Social Problem. Original in Swedish.
} 


\section{Ungdomsvåld: uppkomsten av ett nytt samhällsproblem}

Antalet personer som dömts för misshandel ökade kraftigt under 1900-talet. Misshandelsstatistiken är emellertid känslig för förändringar av vad som uppfattas som brottslig våldsutövning (von Hofer 2006). Ett exempel på hur uppmärksamheten förändrats över tid presenteras i figur 1 nedan som beskriver antalet ledarartiklar om ungdomars stöld- och våldsbrott som de största tidningarna i Sverige skrivit åren 1950-1994 (se Estrada 1997). Fram till 1960-talets mitt dominerar artiklar som utgår från ungdomars stöldbrottslighet. Samtidigt ser vi att det under perioden 1950-1985 inte skrivs särskilt mycket om ungdomar och våld. Sedan mitten av 1980-talet handlar ungdomsbrottslighet i princip bara om våldsbrott.

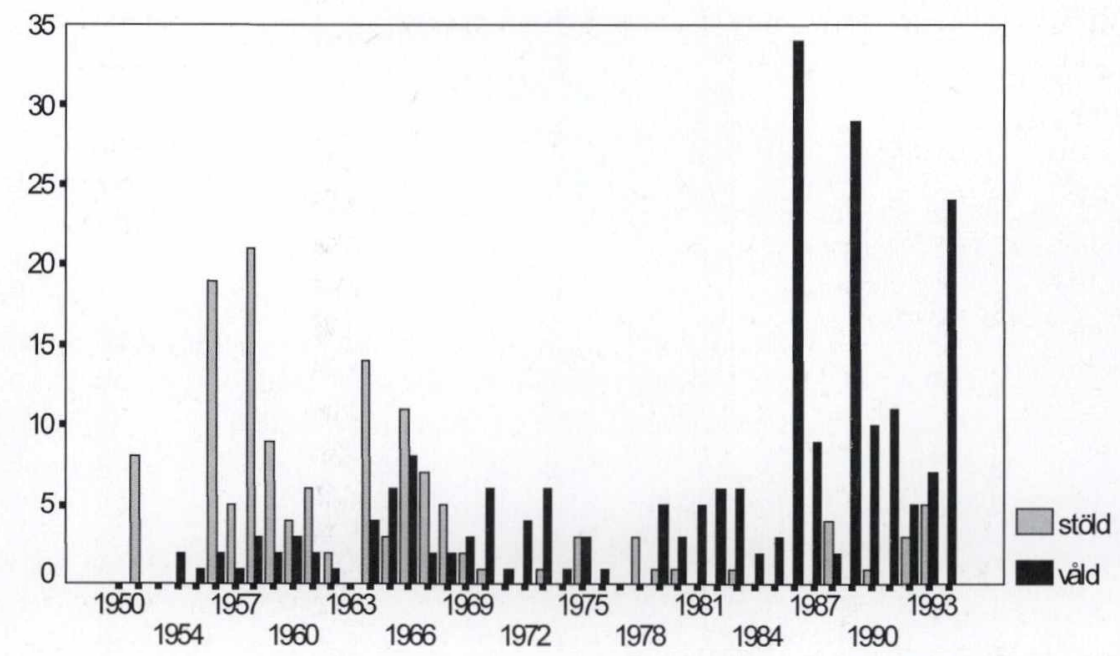

Figur 1. Ledarartiklar om ungdomsbrottslighet: vålds- och stöldbrott 1950-1994.

Om man tittar på vad tidningarna skrev om ungdomsvåld innan, under samt efter 1986 års genombrott framträder klara förändringar av uppmärksamheten kring ungdomsvåld. En stor del av artiklarna åren 1980-85 behandlar domar mot ungdomar som begått grova våldsbrott. Ett exempel är den femåriga fängelsedomen mot en femtonåring som ströp en rullstolsbunden gammal sjukpensionär (1983). Att handlingen är förkastlig är självklart men det som betonas i artiklarna är inte fördömandet mot ynglingen utan mot det hårda straffet. Händelsen används inte heller för att hänvisa till en allmänt ökande eller grövre ungdomsbrottslighet. 
/.../ det är fara å färde om rättssamhället skulle börja använda de fysiskt och psykiskt och moraliskt omognaste eller brutalaste individerna som jämförande måttstock /.../ samhället behöver inte och bör inte använda extrema undantagsfall som avskräckande exempel. (Dagens Nyheter 830504)

Detta citat kan också tjäna som ett bra exempel på hur den unge våldsverkaren karaktäriserades under denna period. I de flesta artiklarna framställs han just som ett problembarn som representerar en minoritet av ungdomarna och som dessutom ofta är känd av myndigheterna. Sommaren 1986 är det plötsligt ett stort antal artiklar som beskriver våldet som grövre och ökande. En ny bild presenteras av den unge gärningsmannen. Han framställs som känslokall och oberäknelig. Den sociala bakgrunden hamnar i bakgrunden.

Den senaste tidens uppmärksammade våldsbrott har inte begåtts av socialt utslagna, berusade eller narkotikapåverkade utan av nyktra, välklädda och fysiskt vältränade ungdomar. Syftet har inte främst varit att komma över pengar eller värdeföremål. Våldet har istället begåtts som en form av perverst nöje. (Aftonbladet 860806)

Genom att de våldsbrott de unga gör sig skyldiga till upplevs som mycket allvarliga och frikopplade från påverkbara sociala förhållanden, vinner idén om inkapacitering gehör. Ungdomar som i allt större utsträckning "väljer" brottslighet är det självfallet svårare att visa någon förståelse för och därmed också lättare att uppröras över.

Om några så kallade värstingar gång på gång rånat och misshandlat människor kan det inte accepteras att de ostört skall få fortsätta med det. Även om de inte blir bättre av att bli inlåsta, så skulle $i$ alla fall offren för deras framfart skyddas en tid. (Dagens Nyheter 900617)

\section{Reaktion på våld som sker i skolan}

Våldet i skolan är inte ett nytt problem. Åtminstone sedan år 1980 går det att vid en genomläsning av tidningen Skolvärlden hitta en bild av omfattande skolvåld, trakasserier, skadegörelse, lärare som vill sluta o.s.v (Estrada 1999). Vidare framgår att det skett en förändring i synen på de våldshändelser som sker i skolan och de reaktioner de bör mötas med. Under första hälften av 1980-talet skiljer tidningens artiklar tydligt mellan allvarliga och lindriga händelser av fysiskt våld. Lindriga fall skulle i princip inte leda till polisanmälning, utan klaras ut internt inom skolan. Under andra hälften av 1980-talet finns en tendens i debatten som går ut 
på att skolan skall ta kontakt med polis även vid mindre ordningsproblem. Under 1990-talet blir detta tydligare. Det argumenteras i det närmaste samstämmigt för att skolan inte längre själva skall söka ta ställning till vad som är ett lindrigt brott utan överlåta detta till polisen. Två uttalanden från chefsjuristerna vid dåvarande skolöverstyrelsen (SÖ) och nuvarande skolverket kan illustrera den förändrade synsättet.

Det inte finns någon allmän skyldighet att polisanmäla en brottslig gärning som redan har begåtts /.../ SÖ tipsar inte om polisanmälan i första hand $i$ en sådan situation /.../ Bättre då att saken klaras upp omedelbart på personlig väg $i$ skolan, om detta är möjligt - skolan har ju stort ansvar för eleverna. (Frank Nordberg i Skolvärlden 1990:5)

När något händer skall man anmäla direkt, inte ta ställning till om det är brott eller inte. Det är polisens sak. (Göte Appelberg i Dagens Nyheter 980120).

\section{Förändrade misshandelsanmälningar}

Genomgången av reaktionen på våld och ordningsproblem som inträffar i skolan visar på en förändring vid övergången mellan 1980- och 1990-talet. Vilka konsekvenser får detta för kriminalstatistiken? De anmälda fallen av skolvåld ökade kraftigt under 1990-talet. En analys av polisanmälningar antyder att förklaringen framför allt ligger i en ökad anmälningsbenägenhet (Estrada 1999). Det har skett tydliga förändringar i rutinerna för anmälning (tabell 1). Skolan gick på kort tid från att vara anmälare i mindre än var tredje brottshändelse till att ligga bakom mer än varannan anmälan. Tillströmningen av antalet fall där skolan anmält våldshändelsen förklarar mer än 80 procent av ökningen. Under 1990-talet anmäls allt fler fall av skolan genom telefonsamtal eller genom fax från färdiga mallar. Det är dessutom tydligt att ökningen av anmälningarna inte är jämnt fördelad efter händelsernas svårhetsgrad. Den kraftiga ökningen av det synliga skolvåldet förklaras av att fler lindriga våldshändelser anmäls. 
Tabell 1. Våld i skolan. Polisanmälningar om misshandel mot 7-14 åringar, 19811997, Stockholm Stad. Procent.

\section{1-1992 1993-1997 Andel av \\ ökningen}

\section{Anmälare}

Anmält av offer eller familj

Anmält av skolan

\section{Anmälningssätt}

Genom besök på polisstation

Polis kallas till skolan

Genom telefon, fax, övrigt

Misshandelns grovhet

Lindrigt våld; våld som lett till

blåmärken och ingen sjukvård

Våld; våld som lett till blodvite eller sjukvårdsbesök

Allvarligt våld; våld som lett till allvarlig skada eller akutsjukvård

21

10 2

\section{Antal händelser}

$80-98$

$194-230$

\section{Samhällets reaktion på brott - en diskussion}

Synen och reaktionen på brottslighet och andra sociala problem varierar över tid. Förändringarna i samhällets åtgärder har på det hela taget lite att göra med hur gärningspersoner beter sig utan hänger i större utsträckning samman med vad som i ett samhälle uppfattas som "rätt" reaktion vid en viss tidpunkt. Kortfattat kan man skilja på två synsätt som är mer eller mindre tydliga i olika länders straffsystem, respektive när ett och samma land jämförs över tid. Å ena sidan kan åtgärder mot exempelvis unga ses som problematiska eftersom reaktionen antas förstärka den unges marginalisering från det övriga samhället. Givet att det samtidigt råder en klart uttalad uppfattning att avvikelsen i grunden bygger på sociala missförhållanden är ett hårt straff från samhället, t.ex. i form av lång inlåsning, en problematisk reaktion som samhället skall undvika. A andra sidan kan, i ett annat samhälle eller vid en annan tidpunkt, samma beteende bemötas på ett helt annat sätt. I fokus ställs istället det faktum att brottet skapat ett lidande hos brottsoffret som samhället måste bestraffa. Givet att den dominerande uppfattningen är att brottslingen 
valt att begå omoraliska handlingar måste samhället reagera bestämt. Därigenom upprättas offret, samhället skyddas tack vare inlåsningen av gärningsmannen och slutligen kan den resoluta reaktionen eventuellt, men detta är alltså inte det primära, leda till att gärningsmannen skräms till laglydigt beteende. Följande citat från två politiska ledare sammanfattar dessa två perspektiv på ett åskådligt sätt.

"Den enda hållbara lösningen [på brottsproblemet] ligger enligt min mening $i$ en politik som botar brister och orättvisor och utjämnar ekonomiska, sociala och kulturella skillnader i samhället"

"Här $i$ världens rikaste land, där det begås mer brott än i något annat land, får vi höra att att lösningen på detta problem är att minska vår fattigdom. Det är inte lösningen...(vi bör) skydda samhället från brottslingen, inte tvärtom. "2

I en intressant artikel menar Murray, Janson och Farrington (2007) att för barn och unga med allvarliga problem så är det betydelsefullt vilken av dessa system som råder i ett samhälle. De jämför hur det gått för barn i England respektive Sverige som under sin uppväxttid fick uppleva att deras föräldrar avtjänade fängelsestraff. Som förväntat hamnade många av dessa barn själva i allvarliga svårigheter. Men deras studie visar även att det mer straffinriktade engelska rättssystemet är förknippat med att fler av dessa unga hamnar i allvarlig kriminalitet. De skriver:

.../"the swedish justice system might have prevented the escalation of criminal careers following parental incarceration. Juvenile justice systems were very different in Sweden and England in the 1950s and 1960s. In Sweden, child welfare, rather than punishment, was the paramount concern in cases of child delinquency/.../Therefore, it is possible that the effects of parental incarceration were mitigated by the welfare-oriented juvenile justice system in Sweden or even exacerbated by the juvenile justice system in England" (Murray et al 2007:145)

Som framgår gäller Murray m.fl (2007) positiva bedömning av Sverige situationen för många decennier sedan. En relevant fråga är om denna beskrivning är lika giltig idag. De två undersökningarna om det svenska samhällets uppmärksamhet på ungdomsvåld som redovisats ovan antyder att det skett en förändring av reaktionen gentemot ungdomar som begår brott. Reaktionsförändringen uttrycks av såväl en kraftig ökning av polisanmälningar mot barn och ungdomars våldsutövning som av medias ändrade uppmärksamhet av brottslighet. Det kanske viktigaste och tydligaste med denna reaktionsförändring är dock att den också har konsekven- 
ser för hur gärningspersoner behandlas i rättsystemet. Allt färre av de unga som döms för brott făr åtalsunderlåtelse och istället har mer ingripande åtgärder ökat tydligt sedan mitten av 1980-talet (Granath 2007). Den förändring som skett kan kortfattat beskrivas som en rörelse från behandling till straffvärde som bärande reaktionsprincip (Tham 1995). En viktig, och samtidigt svårbesvarad, fråga är hur denna reaktionsförändring skall förstås. Avslutningsvis diskuteras några möjliga förklaringsfaktorer.

\section{Brottsutvecklingen}

Den mest uppenbara förklaringen till reaktionsförändringen vore självfallet att reaktion på brott är en enkel funktion av brottsutvecklingen (för en beskrivning av våldsutvecklingen i norden se Estrada 2006). Detta är också den ståndpunkt som ledarskribenter och politiker gärna för fram. Forskningen är dock ovanligt samstämmig i avvisandet av denna förklaring. Den kriminalpolitik som ett land väljer att föra låter sig svårligen kopplas till brottsutvecklingen (Westfelt 2001; Lappi-Seppelä 2007; von Hofer 2008a).

\section{Massmedias betydelse som arena och aktör}

Massmedia spelar en avgörande roll för människors uppfattning av sociala problem. Stanley Cohens myntade i Folk Devils \& Moral Panics (1972) begreppet moralisk panik, vilket fått stor genomslagskraft i forskningen om reaktion på avvikande beteende. Vid en moralisk panik mobiliseras samhällets "rättänkande" aktörer för att ta avstånd från den beskrivna "folk fienden", därmed synliggörs också samhällets moraliska gränser. Forskarna inbjuds till att leverera sakkunniga uttalanden om orsaker och lösningar. Från politiker krävs handlingskraft något som tenderar att resultera i nya reaktionsformer som sägs motverka det aktuella problemet. Kan uppkomsten av en moralisk panik kring brottslighet i allmänhet och våld i synnerhet vara en förklaring till reaktionsförändringen?

Det finns förvisso förhållanden som pekar i den riktningen. Flera av de kännetecken som Cohen beskriver passar exempelvis in på den stora uppmärksamheten kring ungdomsvåld som beskrivits ovan. Uppmärksamheten blossade upp plötsligt och media erbjöd en känsloladdad bild för allmänhet och ansvariga att reagera på. Samtidigt finns det problem med denna förklaring. Flera länder i Europa har sedan 1980-talet redovisat en kraftig ökning av antalet unga som registreras för våldsbrott. I våra skandinaviska grannländer kan man exempelvis se en motsvarande förhöjd uppmärksamhet/känslighet kring denna fråga (Balvig 2000; Christie 2005). Detta antyder att en nationellt avgränsad moralisk panik inte är en fullgod förklaring.

Det är dock helt klart att "det ökande våldet" fått stor genomslagskraft i den 
offentliga debatten. En förklaring skulle därför kunna utgå från Thomas theorem ("If men define situations as real, they are real in their consequences"). Den större uppmärksamheten som våld och brott får uppfattats som en avspegling av problemets utveckling. På detta sätt kan den (mer eller mindre felaktigt) förmedlade bilden av en ständigt ökande brottslighet ses som den reella som politikerna har att reagera på. Detta innebär emellertid också att de bilder som återges av ungdomsbrottsligheten bör uppfattas som bilder med ett viktigt ideologisk innehåll.

I dagens samhällen har massmedia en nyckelposition beträffande förmedlingen av "verklighetsbilder". Några som tidigt förstod mediernas roll var forskarna i den så kallade Birminghamskolan. 1978 publicerade Stuart Hall och hans medarbetare Policing the Crisis. Där analyseras hur den mediala fokuseringen på gaturån utnyttjades av de konservativa i den politiska debatten. Enligt Hall med flera (1978) ligger massmedias betydelse i att de för en majoritet av befolkningen dels definierar vad som är viktiga händelser, dels redogör för hur dessa händelser skall tolkas. Brottsproblemet är spektakulärt och därmed laddat med nyhetsvärde. Vi får mer eller mindre dagligen information om att brottsligheten ökar, blir grövre och går ner i åldrarna vilket skapar en verklighetsbild som kräver en reaktion. Aktioner mot brottsligheten kan därför räkna med mediernas uppmärksamhet, något som inte är oviktigt i politiken. Den mediala arenan kräver samtidigt en viss slagkraftighet av deltagarna. Mot denna bakgrund är det knappast förvånande att den kriminalpolitik som formuleras i medierna tenderar att handla om mer poliser, hårdare straff, nya lagar, nolltolerans o.s.v (Kyvsgaard 1999).

Massmedieforskning har vidare pekat på att nyheter om brott, p.g.a. dessa händelsers uppenbara nyhetsvärde, länge utgjort en viktig del av nyhetsrapporteringen (Pollack 2001). En skillnad mot förr är dock självfallet det ökande flödet av olika nyhetsmedia. Vi kan nu från vårt vardagsrum följa polisens arbete med att fånga brottslingar mer eller mindre i direktsändning vilket inneburit en såväl kvalitativ som kvantitativ förändring av uppmärksamheten kring brottslighet. Allt detta antyder att en del av förklaringen bör sökas hos massmedia som aktör. Samtidigt är det uppenbart att innehållet i medias nyhetsförmedling inte är frikopplad från det omgivande samhället, d.v.s. massmedia är också en arena (Peterson \& Carlberg 1990). Ovan framgick att medias uppmärksamhet av ungdomsvåld ökade vid mitten av 1980-talet, men också att beskrivningen av ungdomsbrottsligheten ändrat karaktär genom att den blivit mindre förstående och mer straffande. Det sistnämnda är en förändring vars förklaring troligtvis bör sökas utanför massmedia.

\section{Brottslighetens rasifiering}

Sverige har under 1900-talet genomgått en förändring vad gäller befolkningssam- 
mansättningen. Från att ha varit ett utvandringsland har Sverige under efterkrigstiden blivit ett invandringsland. Länge dominerades denna invandring av människor från de nordiska grannländerna. Vid mitten av 1970-talet ändrade invandringen karaktär genom en påtaglig ökning av den utomnordiska flyktinginvandringen. En stor del av dessa människor har hamnat i städernas minst attraktiva bostadsområden. Att dessa områden också är drabbade av mer sociala problem och brottslighet än andra områden är sedan länge känt inom den kriminologiska forskningen (Shaw \& McKay 1942; Estrada \& Nilsson 2006).

Att individer med "invandrarbakgrund" är överrepresenterade bland de som registreras för brott i Sverige har också varit känt länge (Sveri 1973). I debatten är det i synnerhet "invandrarungdomars" våldsbrottslighet som uppmärksammats. Pettersson (2002) har visat att fokuseringen på "etniska gäng" är felaktig eftersom faktorer som boendeort och var man går i skolan har större betydelse än etnicitet för vem man begår brott med.

Vad som egentligen mäts med en etnicitetsvariabel är alltså inte klart. Är det betydelsen av biologisk eller kulturell bakgrund och dess påverkan på brottslighet? Och hur ska i så fall en sådan mekanism se ut för att man ska förstå att "invandrares" överrepresentation varit på ungefär samma nivå under flera decennier (von Hofer 2008b:18) samtidigt som sammansättningen av invandrargruppen förändrats? Eller handlar det snarare om de levnadsförhållanden som människor med bakgrund $\mathrm{i}$ ett annat land än Sverige lever under? Givet det forskningen om olika riskfaktorer (Nilsson \& Estrada 2009) kunnat påvisa är det rimligt att utgå från att det bakom överrepresentationen för "invandrarungdomar" i huvudsak finns en påverkan från faktorer som familjeförhållanden, socio-ekonomiska resurser, bostadssegregering, marginalisering och stigmatisering snarare än etnicitet i sig.

Oaktat detta kvarstår det faktum att brottsproblemet $\mathrm{i}$ allt större utsträckning kommit att sammankopplas med hur "invandrarna" är. Kopplingen mellan social utsatthet och brottslighet ges genom en rasifieringsprocess en ny tolkning. Istället för att brottsligheten förstås som ett samhällsproblem som kräver reformer för att förbättra livssituationen för de mest utsatta grupperna läggs skulden på "de andra". Fokuseringen på etnicitet är ett uttryck för det ökade intresset för vilken sorts människor brottslingar är. En utveckling som sker parallellt med minskat intresse för vilka levnadsförhållanden människor som begår brott lever under (se Estrada 2004). För reaktionen på brottslighet har denna utveckling betydelse genom att skillnaden mellan "Vi" - de laglydiga, och "De andra" - brottslingarna, tillåtits bli påtagligare. Med större avstånd minskar såväl möjligheterna som behovet av förståelse. 
Högervåg och brottsbekämpning som lösning på välfärdsstatens legitimitetskris Boréus (1994) visar i sin avhandling att svensk samhällsdebatt kom att präglas av en "nyliberal högervåg" under 1980-talet. Åkerström (1996) menar att den stora uppmärksamhet "våldet" fått kan beskrivas som målrationell snarare än panikartad. Våldsbrottsligheten utgör stoff i politiska kampanjer, i organisationers profilering och i enskilda befattningshavares karriärer. Simon (2007) har målande kallat denna utveckling för "Governing through Crime". Uppmärksamhet av våldsbrottslighet har blivit ett strategiskt verktyg i den offentliga debatten. Hänger detta ihop med den politiska högervågens kritik av den socialdemokratiska välfärdsstaten?

Enligt Beckett (1997) ligger förklaringen till vår tids uppmärksamhet kring brottsligheten just på den politiska arenan. Beckett visar att brottsligheten har fyllt en viktig roll i den amerikanska högerns kritik av välfärdsstaten. Kritiken har bland annat gått ut på att samhället skapar individer utan incitament att lyfta sig ur fattigdom. I "den ökande brottsligheten" har högern funnit ett problemområde där den kan exploatera de känslor av obehag som brottslighet väcker för att vinna nya grupper av väljare. Beckett visar på hur effektivt denna politiska användning av brottsligheten har slagit igenom i USA. Något som lett till förfärande höga fångtal i allmänhet, och för minoriteter i synnerhet (Christie 1994; Waquant 2004).

Thams analyser $(1995,1998,1999)$ antyder att "högervågen" och välfärdsstatens legitimitetskris utgör viktiga beståndsdelar i förståelsen av den svenska kriminalpolitikens utveckling (se också Kyvsgaard 1999). Tham menar att kriminalpolitiken inte enbart skall ses som en effekt av de allmänpolitiska förändringarna i samhället utan också som ett medel att påverka denna utveckling. Kriminalpolitiken har å ena sidan utgjort en strategisk arena för nyliberal kritik mot välfärdsstaten. Viktiga värden i marknadsstaten - ansvar och individualism - har här kunnat lyftas fram som brottsförhindrande samtidigt som välfärdsstatens grundtanke jämlikhet - kan anklagas för att vara brottsalstrande (Tham 1995, 1998). En viktig iakttagelse som Tham (1999) gör är att socialdemokratin, i takt med att utrymmet avtagit för att lösa de problem som politiken traditionellt haft mandat för, också funnit användning för uppmärksamheten kring brottsproblemet. (Se också Estrada 2004).

Habermas ([1976] 1984) diskuterade tidigt uppkomsten av en legitimitetskris för välfärdsstaten. Enligt Habermas krävde legitimiteten av efterkrigstidens demokratiska samhällssystem en politik som begränsade den fria kapitalismens avigsidor. Detta skedde framförallt genom en politik där staten tog allt större åtaganden inom ekonomin. Av stor vikt var utbyggnaden av den sociala tryggheten, vilken välfärdsstatens legitimitet vilar på. Härigenom uppstod dock ett dilemma, menar Habermas. Staten var tvungen att dra på sig stora ekonomiska bördor som endast kunde finansieras genom en ekonomisk tillväxt som var avhängig en allt friare ka- 
pitalistisk marknadsekonomi. Detta skapade i sin tur problem som välfärdsstaten åtagit sig att mildra. Resultatet blir ett behov av kontinuerlig tillväxt av såväl det ekonomiska som det politiska och administrativa systemet. Om staten inte lyckas med att lösa detta dilemma, något som påtagligt försvårats av den ökade avregleringen av ekonomin, då kan en legitimitetskris inte undvikas, menar Habermas.

Som en konsekvens av detta har det blivit viktigare för makthavarna att hitta vägar att undvika, eller åtminstone begränsa, legitimitetsbortfallet. En möjlighet som står till buds är att fokusera det offentliga samtalets fokus till arenor där legitimitetsvinnande handlingskraft är möjlig att påvisa. Enligt Bauman (2000) har brottsligheten och kriminalpolitiken just blivit en sådan arena. Bauman menar att globaliseringens huvudsakliga konsekvens är osäkerhet. Där finns ängslan om hur framtiden kommer te sig, krav på individuell risktagning istället för färdiga kollektiva val, otrygghet på arbetsmarknaden o.s.v. Det handlar alltså om osäkerhet i vid bemärkelse. Samtidigt finns en tydlig tendens att denna allmänna osäkerhet kanaliseras till en rädsla för individens personliga säkerhet. Bauman noterar hur lämpligt detta är för den politiska makten. Politikerna framstår som handlingskraftiga om vår tids osäkerhet görs till en rädsla för brott istället för en förlust av grundläggande social trygghet. Härigenom kan politiken återerövra åtminstone en del av den legitimitet som gått förlorad under den nyliberala eran.

Reaktionsförändringen kan alltså förstås mot bakgrund av å ena sidan de strukturella förändringar som påverkat vad som är möjligt för makthavarna att göra, vilket kommit att delvis urholka statens legitimitet inför medborgarna. $\AA$ andra sidan av en ideologisk "högervåg" som påverkat den svenska offentliga debatten. Inom social- och kriminalpolitiken har denna ideologiska glidning bl.a. lett till förändrad syn på gärningsmannen som offer för dålig uppväxt och problematiska omständigheter, till en individ som "väljer" att begå brott mot andra människor (se Estrada 2004 för en beskrivning av den politiska dynamiken bakom denna förändring). Stämplingsperspektivets tveksamhet gentemot ingripanden från myndigheter har ersatts av ett kontrollteoretiskt perspektiv där tidiga, tydliga och konsekventa åtgärder uppfattas som viktiga för det brottsförebyggande arbetet.

Brottsproblemet har genom "högervågen" och välfärdsstatens legitimitetskris fått en allt större betydelse som en arena, till skillnad från den traditionella socioekonomiska, att visa handlingskraft i. Att göra något mot "den ökande brottsligheten" blir ett sätt att vinna tillbaka en del av den förlorade legitimiteten för makthavarna.

\section{Problemet med en alarmistisk kriminaldebatt}

Avslutningsvis vill jag kort peka på ett par problem med den politiserade använd- 
ningen av brottsproblemet. För det första kan en oavsedd konsekvens av statens fokusering på brottsbekämpning vara förlorad snarare än vunnen legitimitet. I den mån medborgarna fås att uppfatta brottsligheten som ett av de allvarligaste samhällsproblemen, ett problem som dessutom p.g.a. massmedia ständigt anses bli allt allvarligare, har man också skapat sig ett trovärdighetsproblem som inte fanns tidigare. Statens legitimitetskris och oförmåga att leverera trygghet riskerar därmed att bli tydligare snarare än tvärtom. Den uppenbara faran är att en sådan situation leder till att utrymmet för en humanistiskt kriminalpolitik blir än mindre. För när kommer allmänheten att uppfatta att straffen är hårda nog enligt de politiker som ängsligt lutar sig mot opinionsundersökningar (Jerre och Tham 2010)?

För det andra finns en uppenbar risk att en stor uppmärksamhet kring brottslighet i kombination med betoningen på lag och ordning leder till ökad stigmatisering av de grupper som kommit att förknippas med brottsproblemet, d.v.s. ungdomar och invandrare $i$ allmänhet och invandrarungdomar i synnerhet. En av de mest intressanta aspekterna i Hall m.fl. analys (1978) är att medierna pekade ut de unga svarta männen som gärningsmän. Jämförelsen med den aktuella uppmärksamheten kring "invandrargäng" och våld är självklar. Den ökade kontroll som följde mediernas behandling av gaturånen i England betydde, enligt Hall m.fl., att kontrollen av den svarta befolkningen tilltog. Därigenom ökade man samtidigt kontrollen mot de fattiga, arbetslösa och deras barn. De negativa konsekvenserna av samhällsutvecklingen kom på så sätt att kontrolleras polisiärt istället för att reformeras politiskt.

På senare tid har rasismen ökat i Västeuropa. På yttersta högerkanten exploateras medborgarnas oro över samhällsutvecklingen samtidigt som de statsbärande partierna stiftar hårdare immigrationlagar (se t.ex. Abiri 2003). Detta väcker misstro bland minoritetsgrupperna. Det finns en risk att "majoritetsbefolkningen" och "invandrare" börjar se varandra med större misstänksamhet. "Svenskar" ser "invandrare" som kriminella, arbetsskygga välfärdsslukare. "Invandrare" ser "svenskar" som rasister som stöder ett samhälle diskriminerar människor bara på grund av deras ursprung. Exploateringen av brottsfrågan har en uppenbar roll $\mathrm{i}$ denna process. Samhället riskerar därmed att splittras efter etnicitet, och i denna spricka frodas de sämsta politiska lösningar våra samhällen känner till. 


\section{Litteratur}

Abiri, E (2003): Asylrätten: ett hot mot rikets säkerhet? I Flyghed \& Hörnqvist (red.) Laglöst land. Terroristjakt och rättssäkerhet i Sverige, Smedjebacken: Ordfront.

Balvig F. (2000): Det Voldsomme Samfund. Om vold som problem og faengsel som lösning. vol. 1 \& 2. Köpenhamn: Jurist- og Okonomforbundets Forlag.

Bauman, Z. (2000): Globalisering. Lund: Studentlitteratur.

Beckett, K. (1997): Making Crime Pay. Law and Order in Contemporary American Politics. New York:Oxford University press.

Boréus, K. (1994): Högervåg. Nyliberalism och kampen om språket i svensk offentlig debatt 1969-1989. Stockholm: Tiden.

Christie, N. (1994): Crime Control as Industry. Towards GULAGS, Western Style. 2 uppl. London: Routledge.

Christie, N. (2005): Lagom mycket kriminalitet. Stockholm : Natur och kultur.

Cohen, S. (1972): Folk Devils and Moral Panics. The Creation of the Mods and Rockers. Oxford: Chaucer Press.

Estrada, F.(1997), "Ungdomsvåld: upptäckten av ett samhällsproblem. Ungdomsbrottslighet i svensk dagspress 1950-1994", Sociologisk Forskning, 34: 51-72.

Estrada, F. (1999): Ungdomsbrottslighet som samhällsproblem. Utveckling, uppmärksamhet och reaktion. Kriminologiska institutionen, Stockholms universitet.

Estrada, F (2004) "The Transformation of the Politics of Crime in High Crime Societies" European Journal of Criminology, vol 1:4:419-444.

Estrada, F. (2006): Trends in violence in Scandinavia according to different indicators. British Journal of Criminology, vol 46:3; 486-504.

Estrada, F \& Nilsson, A. (2006): Segregation och utsatthet för egendomsbrott betydelsen av bostadsområdets resurser och individuella riskfaktorer. Institutet för Framtidsstudier, arbetsrapport 2006:5.

Granath, S. (2007). Rättsliga reaktioner på ungdomsbrott 1980-2005. Stockholm: Stockholms Universitet, kriminologiska institutionen.

Habermas, J. [1976](1984): Den rationella övertygelsen. En antologi om legitimitet, kris och politik. Stockholm: Akademilitteratur.

Hall S., Critcher C., Jefferson T., Clarke J. \& Roberts B. (1978): Policing the Crisis. Mugging, The State, and Law and Order. London: The MacMillan Press. von Hofer, H. (2006). "Ökat våld och/eller vidgade definitioner?" Nordisk Tidskrift for Kriminalvidenskab, 93:193-208.

von Hofer, H.,(2008a): "Fångtal och kriminalpolitik", i Elholm, Thomas m. fl. (red.) Ikke kun straf. Jurist- og Økonomforbundets Forlag, Köpenhamn, s. 221-230. 
von Hofer, H.,(2008b): Brott och straff i Sverige. Stockholm: Stockholms Universitet, kriminologiska institutionen.

Jerre, K. \& Tham, H. (2010): Svenskarnas syn på straff. Rapport 2010:1. Stockholm: Stockholms Universitet, kriminologiska institutionen.

Kyvsgaard, B. (1999), "Motsättningarnas kriminalpolitik. Pendling mellan defensiv och offensiv modell", i Atta reflektioner om kriminalpolitik, Stockholm: Brå.

Lappi-Seppelä, T. (2007). Tillit, välfärd och politisk ekonomi. Nordisk tidsskrift for kriminalvidenskab, 94:3:399-429.

Murray, J., Janson, C-G., \& Farrington, D. (2007): Crime in adult offspring of prisoners. A cross-national comparison of two longitudinal samples. Criminal Justice and Behavior, vol 34:133-149.

Nilsson, A. \& Estrada, F. (2009). Kriminalitet och livschanser. Uppväxtvillkor, brottslighet och levnadsförhållanden som vuxen. Arbetsrapport/Institutet för Framtidsstudier; 2009:20

Peterson, O. \& Carlberg, I. (1990): Makten över tanken. Stockholm: Carlssons.

Petterson, T. (2002): Tre perspektiv på brottsliga nätverk: supporterbråk, etnicitet och genus. Kriminologiska institutionen, Stockholms universitet.

Pollack, E. (2001), En studie i Medier och Brott. Stockholm: Stockholms universitet, JMK.

Shaw, C.R. \& McKay, H.D. (1942). Juvenile Delinquency and Urban Areas. Chicago: The University of Chicago Press.

Simon, J. (2007): Governing Through Crime. How the War on Crime Transformed American Democracy and Created a Culture of Fear. Oxford University press.

Sveri, B. (1973): "Utlänningars brottslighet. En kriminalstatistisk jämförelse mellan svenska och utländska medborgare", Svensk Juristtidning, 58, s. 279-310.

Tham, H. (1995): "Från behandling till straffvärde. Kriminalpolitik i en förändrad välfärdsstat." I Victor, D. (Red.), Varning för straff. Om vådan av den nyttiga straffrätten, s. 78-109. Stockholm: Fritzes.

Tham, H. (1998): "Brottslighet och välfärdsstat - exemplet Sverige och Storbtittanien", I von Hofer, H. (Red.), Brottsligheten i Europa, s. 131-159. Lund: Studentlitteratur.

Tham, H. (1999): "Lag och ordning som vänsterprojekt? Socialdemokratin och kriminalpolitiken.” I BRÅ (Red.), Atta reflektioner om kriminalpolitik, s. 96117. Stockholm: Brottsförebyggande rådet.

Wacquant, L. (2004): Fattigdomens fängelser. Eslöv: Symposium.

Westfelt, L. (2001): Brott och straff i Sverige och Europa. Stockholm: Stockholms Universitet, kriminologiska institutionen. 
Åkerström , M. (1996): "'Våldet' en moralisk panik? Emotionellt engagemang eller publika tyckanden?", I Åkerström, M. (Red.), Kriminalitet Kultur Kontroll, s. 226-244. Stockholm: Carlssons.

\section{Noter:}

Olof Palme, 1972

Ronald Reagan 1984

Adress

Kriminologiska institutionen, Stockholms universitet 10691 Stockholm

Sverige

Felipe.Estrada@criminology.su.se 